\title{
Rural Infrastructure and Agricultural Market Integration in the United States: A long run perspective
}

\author{
by \\ Paul Sharp \\ and \\ Martin Uebele
}

Discussion Papers on Business and Economics

No. $10 / 2013$

\author{
FURTHER INFORMATION \\ Department of Business and Economics \\ Faculty of Social Sciences \\ University of Southern Denmark \\ Campusvej 55 \\ DK-5230 Odense M \\ Denmark \\ Tel.: +4565503271 \\ Fax: +4565503237 \\ E-mail: lho@sam.sdu.dk \\ http://www.sdu.dk/ivoe
}




\title{
Rural Infrastructure and Agricultural Market Integration in the United States: A long run perspective $^{1}$
}

Paul Sharp, Department of Business and Economics, University of Southern Denmark

Martin Uebele ${ }^{2}$, Faculty of Arts, Economic and Social History, University of Groningen

\begin{abstract}
In recent years, there has been an increasing focus by policymakers on rural infrastructure in the United States, including most recently tax credits to encourage investment. Previous work has documented the importance of railroad expansion for nineteenth century development, and demonstrated that policy failure led to the disintegration of agricultural markets in the interwar period, with potentially serious macroeconomic consequences. Using a database of average prices by state of seven agricultural products for the period ca. 1870-2010, we extend this analysis to the post-Second World War period. We find a striking disintegration in recent decades, as measured by price dispersion, which we attribute to decades of underinvestment, particularly in railroads. We thus provide strong support for the present policy focus on investment in rural infrastructure.
\end{abstract}

Keywords: United States, agriculture, market integration, rural infrastructure

JEL codes: N52, N72, Q13, R42

\footnotetext{
${ }^{1}$ We would like to thank conference and seminar participants for valuable advice and suggestions. Moreover, we would like to thank Andreea-Alexandra Maerean and Tim Grünebaum for valuable research assistance.

${ }^{2}$ Corresponding author: Oude Kijk in 't Jatstraat 26, 9712 EK Groningen, Netherlands, m.uebele@rug.nl.
} 


\section{Introduction}

In its latest 'Report Card for America's Infrastructure'3, the American Society of Civil Engineers (ASCE) awarded the United States a D+ for 2013. As bad as this sounds, the Economist ${ }^{4}$ noted that this is in fact the first time since 1998 that the grade has risen. This modest improvement was brought on by increased investment, although the ASCE still believes that $\$ 3.6$ trillion of investment is needed before 2020. Of course, as the Economist noted, civil engineers have a vested interest in this. There is, however, plenty of evidence that America's infrastructure has been suffering from underinvestment, and in fact this was explicitly recognized by Congress in 2011, when they enacted a 50 percent tax credit to encourage investment in small railroads (National Grain Car Council 2011, p. 14). This reflected recognition of the value of such services both in terms of lower costs, but also for the development of rural areas, and for the environment. This appears to have started to pay off, since freight railroads are one of the few areas singled out for praise in the ASCE report.

The present work presents a novel way of measuring the economic impact of the deterioration in infrastructure, using a simple approach taken from the economic history literature. We thus give a long run perspective to this story, and set it within the context of the literature on the importance of market integration. We argue that agricultural markets for some commodities have been disintegrating since the Second World War, something that is generally ignored in the standard textbook accounts of the period (see for example Gardner 2002, who only considers corn prices). This finding is, we believe, a strong justification for a continued focus on the role of rural infrastructure.

The long run perspective allows us to put our findings within the context of the historical importance of transportation for the integration and development of the American economy. It is now widely accepted that the fall in transportation costs with the advent of steam shipping and rail services was of great importance for the integration and development of both the

\footnotetext{
${ }^{3}$ http://www.infrastructurereportcard.org/

4 'D (for dilapidated) plus', Economist, April 6 ${ }^{\text {th }}, 2013$
} 
American and the world economy in the last decades of the nineteenth century. ${ }^{5}$ Recent work by Federico and Sharp (2013) demonstrates that transportation regulation between the wars led to market disintegration within the United States, as changes permitted to nominal freight rates failed to keep track of falling commodity prices during a period of deflation, thus leading to high real transportation costs. They also demonstrate that the welfare costs of this for the American economy were probably rather high.

We extend these previous analyses and look at market integration for American agricultural markets from the 1860 s to today. We use data on annual prices by state of seven agricultural commodities as published by the US Department of Agriculture since 1866. We plot the coefficient of variation, as a measure of price dispersion, and decompose this into within- and between variance for four geographic regions. The story is not just one of increasing integration over time, which is what one might initially suspect. In fact, the norm seems to be disintegration after the Second World War. This is consistent with the findings of Bukenya and Labys (2005) for the world markets of various commodities, and of Hickey and Jacks (2011) for the case of Canada.

We believe that the increasing price dispersion we document below is likely explained by increasing transportation costs. In section 2 we present the empirical evidence for the disintegration of American agricultural markets since the Second World War. Section 3 relates our findings to the current policy debate. Section 4 considers alternative explanations for our findings. Section 5 concludes.

\section{Market Disintegration and the Decline of Rail}

\subsection{Methodology and data}

The concept of market efficiency is central to agricultural economics and is related to the concept of market integration, which has been a key focus of economic historians in recent

\footnotetext{
${ }^{5}$ See for example O'Rourke and Williamson (1999), Federico and Persson (2007), and Uebele (2011). For a longer run perspective see Sharp and Weisdorf (2013).
} 
years. However, while the agricultural economics literature has focused primarily on the speed of adjustment to the law of one price equilibrium (see Ravallion 1986 for one of the seminal contributions), economic historians have also looked at price dispersion (e.g. Federico 2012). In this spirit, we consider that periods of price integration and disintegration simply reflect adherence to the weak law of one price, where $p_{i}=p_{j}+T_{i j}$, where $T_{i j}$ may be referred to as transaction costs including all costs of arbitrage. Even within America, these are not inconsiderable. ${ }^{6}$

In a recent survey article, Myers et al (2010, p. 388) give a short overview of the contributions made by agricultural economists to the question of spatial market efficiency. The consensus seems to be that efficiency is not adhered to consistently over time, but that there is less understanding of the reasons for these deviations. From the perspective of scholars more familiar with the economic history literature, this is perhaps not surprising. The work on the speed of adjustment has usually focused on bivariate relationships between high frequency prices over a relatively short period for, for example, city pairs. Despite the challenge to create a 'generalisation to a multivariate model considering adjustment of more than two prices' from the pioneer of the modern Threshold Vector Error Correction Models (TVECMs) (Meyer 2004, p. 334), little progress has been forthcoming, despite considerable technical progress in other dimensions (see for example Goodwin and Piggott 2001). A notable exception is Jacks (2004, 2005), who employs an asymmetric-threshold error-correction-mechanism (ATECM) to examine market efficiency between a number of European and American markets for the case of wheat, but the limitation is still that each market pair has to be considered separately. We argue here that a long term perspective encompassing many markets simultaneously for a variety of commodities gives insights that other approaches do not, even if we are then forced to sacrifice market efficiency (in terms of speed of adjustment) as our parameter of interest. Besides, Federico (2012) has argued convincingly that price dispersion (re-interpreted in dynamic terms as price convergence) is of far more economic significance than market efficiency, since it is relative prices which determine patterns of specialization and trade, and thus have a large

\footnotetext{
${ }^{6}$ In fact, Wolf (2000) documents home bias in trade even between American states, thus implying that there are barriers to trade which have nothing to do with formal trade barriers, exchange rates, culture or institutions.
} 
impact on long run growth, and not the missed arbitrage opportunities captured by efficiency analyses, however big the welfare losses.

We thus proceed to look for evidence of commodity market integration by considering the absolute price differences of homogenous products between different locations. Our approach is a multivariate measure of market integration, meaning that we do not rely on bivariate comparisons of prices implying a large number of possible pairs to look at, but examine market integration for the whole set of markets. We also distinguish between market integration at different levels, i.e. between national and regional integration. We thus allow for conclusions about whether market integration or disintegration was a process originating from convergence or divergence between or within regions.

The measure we use is simple, the coefficient of variation (COV). This is the cross-sectional standard deviation of a sample of price observations divided by the sample mean:

$$
\operatorname{cov}=\frac{\sigma}{\mu}
$$

According to the law of one price, prices of the same good should be the same in different places due to arbitrage, if transaction costs are zero. Thus, price dispersion should decrease with transportation costs and result in better integrated markets.

This measure of price divergence can be decomposed into within- and between variance at various regional levels; i.e. northeast (NE), midwest (MW), south (S) and west (W). We depict national cross-sectional price variance by $\sigma^{2} u s$, consisting of within- and between variance of four geographic regions (see Figure 1):

$$
\sigma_{u S}^{2}=\sigma^{2} w+\sigma_{B,}^{2}
$$

where between region variance is using the squared difference between regional and national price means $\sigma_{B}^{2}=\sum_{r=1}^{4}\left(\mu_{r}-\mu_{U S}\right)^{2} N_{r}$, with $r=[N E, M W, S, W]$, and $\mu_{\mathrm{r}}=\frac{1}{N_{r}} \sum_{i=1}^{N_{r}} \mu_{i}, i=1, \ldots, N_{r}$, 
and within-regional variance is the sum of regional variances $\sigma^{2}{ }_{W}=\sum_{\mathrm{r}=1}^{4} \sigma_{W, r}^{2}$, which consist of the squared differences between state prices and regional means $\sigma^{2}{ }_{w, r}=\sum_{\mathrm{i}=1}^{N_{r}}\left(\mu_{\mathrm{i}}-\mu_{\mathrm{r}}\right)^{2}$.

[Figure 1 about here]

According to this rule we calculate shares of variance between and within regions, and apply them to the simple COV, thus obtaining within and between price distributions for every year.

Our data are mostly taken from the ATICS dataset, collected and described in detail by Cooley et al (1977), which was kindly made available to us by Stephen J. DeCanio. This covers all states between 1866 at the earliest and 1970 at the latest. We then supplement it with more recent data taken from the USDA (the National Agricultural Statistics Service, NASS ${ }^{7}$ ).

The database refers to farm gate prices and after 1933 they include proceeds from purchases under the Agricultural Adjustment Act and other government support programs. They thus measure directly the effect of price convergence on the welfare of farmers. Farm gate prices are bound to differ from (city) market prices by the transportation costs to cities and they might be noisier than comparable market prices, but we follow Federico and Sharp (2012) in assuming that the differences are not big enough to jeopardize the conclusions of our analysis.

The ATICS database covers 18 crops (barley, buckwheat, cotton, corn, flaxseed, 'all hay', hops, oats, peanuts, potatoes, rice, rye, soybeans, sweet potatoes, sugar-beets, tame hay, tobacco, and wheat). However, we omit series which are too short, which are for commodities of which very little are grown, or which are only grown in a small number of states. We thus focus on seven main crops ('all hay', barley, corn, oats, potatoes, rye, and wheat).

\subsection{Results}

${ }^{7}$ http://www.nass.usda.gov/ 
Figure 2 plots the COV for our seven crops. Although the pre-First World War integration and interwar disintegration are generally discernible, the pattern after the Second World War is more mixed. However, disintegration is obvious for most, and this has been on both the regional and national levels, which can be seen when comparing the green and blue areas. The exceptions are rye, which is a fairly marginal crop in the United States, and corn.

[Figure 2 about here]

It turns out that corn is an interesting and unusual case. Although we confirm Gardner's (2002) result for corn, as mentioned above, this is due to factors very specific to this market. In recent years, it has become an important source of ethanol for fuel, and Scott and Irwin (2008) argue that it might in fact be increasingly relevant to consider corn prices as being determined by the price of crude oil. It seems that its exposure to such a highly competitive market, where corn is increasingly traded not as the grain, but as fuel, has led to a pattern of price dispersion very different to that of the other crops. This aside, market disintegration seems to be the norm.

\section{Market Disintegration and the Policy Debate}

Our application of the methods used in the economic history literature to long run data for American agricultural markets thus results in a surprising finding: agricultural markets have been disintegrating over the last half century. This interpretation seems to run contrary to what one might intuitively expect, and popular literature about advances in transport and communication technology run counter to the notion of rising price gaps. In fact, rail freight rates have fallen in recent decades, largely due to deregulation (Surface Transportation Board, 1998, 2000). Although this trend has been partially reversed since 2004, largely due to rising input prices (particularly fuel) and declining productivity growth, it is nevertheless the case that 
rail transportation has become considerably cheaper (Surface Transportation Board 2009), a story which is confirmed by the National Grain Car Council ${ }^{8}$ in a white paper from 2011.

Railroads are no longer, however, the whole story. Already in 1994, Hough (1994, pp. 14-15), in her detailed account of the logistics of the US wheat market, described how lack of public investment in infrastructure in the US was a serious problem. She recommended investment in the water and rural road network, and described how 38,000 miles of railroad had been abandoned between 1985 and 1994, including those servicing grain elevators. She predicted that this would mean that grain must increasingly be loaded onto trucks, which both have a higher unit cost and which damage the already fragile road network.

Hough's predictions do in fact seem to have been borne out, as is apparent by a look at the detailed accounts of the deliberations of the National Grain Car Council since 1994. Today, rail only accounts for one third of US grain and oilseed movements, the rest being with trucks (over 50 percent) and barges (about 20 percent) (National Grain Car Council 2011, p. 2). The reason for this is the gradual disappearance of the small family farm since the Great Depression, which caused rail companies first to abandon certain rural lines and later to remove the tracks (National Grain Car Council 2011, p. 9). Trucks then served these areas.

High unit freight costs imply market disintegration, and would seem to explain our findings. There are, however, other potential explanations, which we consider in the next section.

\section{Alternative Explanations for the Post-War Market Disintegration}

We have chosen to frame our analysis within the context of the role of transaction costs driving a wedge between prices, and we feel that this is indeed the most simple and likely explanation for our findings. We can, however, imagine other possible reasons why markets might have disintegrated during this period.

\footnotetext{
${ }^{8}$ The National Grain Car Council was founded by the former ICC 'and is made up of a balanced representation of executives knowledgeable in the transportation of grain', whose members gather at least once a year to discuss issues affecting the grain transportation industry.
} 
First, we cannot ignore the fact that there have been significant developments in the regulatory environment since the Second World War (see for example US Department of Agriculture, 2005, p. 10). In particular, agriculture and farm policy has seen big changes since the 1933 Agricultural Adjustment Act, when the first 'farm bill' established the New Deal mix of commodity-specific price and income support programs. From this date on, the prices of agricultural goods were not simply determined by market conditions.

After the War, the 1949 Agricultural Act established a policy of high, fixed-price supports and acreage allotments as a permanent feature of farm policy. This was followed by the 1954 Agricultural Act, which introduced flexible price supports to commodity programs. The 1965 Food and Agricultural Act introduced new income support payments in combination with reduced price supports and continued supply controls, and finally the 1973 Agriculture and Consumer Protection Act introduced target prices and deficiency payments to replace price supports, coupled with low commodity loan rates, to increase producer reliance on markets and allow for the free movement of commodities at world prices. ${ }^{9}$ We do not, however, see any reason why these price support measures should have resulted in higher regional price gaps.

A more likely alternative explanation concerns the role of sticky prices. Jacks and Hickey (2010) studied the relationship between nominal price rigidities and price dispersion with data for Canada, 1910-1950, and 1978-1993. They found that nominal rigidities are negatively correlated with spatial price dispersion confirming theoretical predictions found in the literature. Contrary to stylized facts they then found that price stickiness in Canada was larger in times of higher inflation between 1910 and 1950, a peculiarity they connect to the generally deflationary - and therefore fundamentally different - macroeconomic environment. They also found that distance declines as an explanation for spatial price variation between the interwar and the postwar years, but that price dispersion increased throughout the 1980s. This corresponds closely to our findings of greater price dispersion in the United States after the War. The authors rule out changes in trade costs as an explanation of their findings, since an

\footnotetext{
${ }^{9}$ See Dimitri et al (2005) for more on this.
} 
interaction term of time and distance does not yield significant coefficients. Instead, they propose changes in the competitive environment as a more likely candidate reason.

Unfortunately, our annual data set does not allow for calculating nominal rigidities, such as frequency of price changes, which are as meaningful as Jacks and Hickey (2010) obtained from monthly data. We are not aware of any study of price stickiness based on annual price observations and therefore must leave this avenue for future research when higher frequency data sets are available. We do, however, feel that our explanation is more simple and likely than the role of nominal rigidities in this case. In particular, although the number of farms declined steadily from over 6,000 in 1920 to around 2,000 in 1990, and farm size roughly tripled in the same period, we believe that a market with 2,000 sellers is still far from resembling an oligopoly. Furthermore, the market for foodstuffs is more complex and involves wholesale and retail sectors which underwent significant changes themselves in the period under question. In fact, in the sticky price literature, the agricultural sector is usually seen as the most competitive, where market power arising from monopolistic competition is believed not to exist (Rottemberg 1982, p. 1196). Thus, producer market power must be consistent with an overall number of 2,000 farms in the US or else it should be ruled out as a candidate explanation for increasing price dispersion.

A third alternative explanation concerns the role of weather shocks, since a changed distribution of supply shocks can lead to changes in market integration. Kaylen, Wade and Frank (1992) acknowledge that weather shocks have indeed changed after the Second World War and test the relationship between corn yields, input prices and weather variance for two periods, 1949-68 and 1969-88, and find that both weather shocks and the transmission of shocks to yields have changed. They do not consider the resulting spread of prices between regions or states, however, nor do they discuss the impact of yields on farm gate prices. A screening of the literature on weather effects shows that the change of spatial variance over time is not the main focus of climatologists or of agricultural economists. Instead, the cross-sectional variance is simply being exploited to estimate model parameters (such as for example by Schlenker and Roberts 2006). Fox et al (2011) consider the effects of weather shocks on the 'unfettered 
markets' of the pre-1933 period. Although they find that there were differential effects by commodity, there is nothing to suggest that the short run effects they consider should impact on long run price convergence or divergence.

\section{Conclusion}

Our analysis contributes to the literature on market integration by combining the long run approach of the economic historian with data for agricultural produce in one of the world's most important agricultural markets: the United States. We find evidence which supports Federico and Sharp's conjecture that the integration of American agricultural markets was and is not necessarily a fait accompli - even for recent decades. The story of market integration is in fact one of progress and reversals.

We attribute the recent market disintegration to underinvestment in rural infrastructure. It remains to be seen whether or not recent policy changes will reverse the trends we observe in the data, but we believe that the present paper should add grist to the mill of those who are pressing for more such measures. 


\section{References}

Cooley, T.F., S.J. Decanio and M.S. Matthews (1977). 'ATICS: An Agricultural Time Series-Cross Section Dataset.' NBER Working Paper No. 197.

Crucini, M.J., M. Shintani, and T. Tsuruga (2010). 'The Law of One Price without the Border: The Role of Distance versus Sticky Prices.' Economic Journal 120:544, pp. 462-480.

Dimitri, C., A. Effland, and N. Conklin (2005). 'The 20th Century Transformation of U.S. Agriculture and Farm Policy'. USDA Electronic Information Bulletin Number 3.

Federico, G. and K.G. Persson (2007). 'Market Integration and Convergence in the World Wheat Market, 1800-2000.' In Hatton et al (2007).

Federico, G. and P.R. Sharp (2013). 'The Cost of Railroad Regulation: The Disintegration of American Agricultural Markets in the Interwar Period.' Economic History Review (forthcoming).

Fox, J.F., P.V. Fishback and P.W. Rhode (2011). 'The Effects of Weather Shocks on Crop Prices in Unfettered Markets: The United States Prior to the Farm Programs, 1895-1932.' Chapter in NBER book The Economics of Climate Change: Adaptations Past and Present, G.D. Libecap and R.H. Steckel (eds.), pp. 99-130.

Gardner, B.L. (2002). American Agriculture in the Twentieth Century: How It Flourished and What It Cost. Cambridge, MA: Harvard University Press.

Good, D. and S. Irwin (2008). 'The New Era of Corn, Soybean, and Wheat Prices.' MOBR 08-04, Department of Agricultural and Consumer Economics, University of Illinois at UrbanaChampaign

Hatton, T.J., K.H. O'Rourke and A.M. Taylor (2007). The New Comparative Economic History: Essays in Honor of Jeffrey G. Williamson. Cambridge, MA: MIT Press.

Hough, J.A. (1994). Logistics of the U.S. Wheat Industry. North Dakota State University. 
Huneke, W.F., M.J. Boyles, W.J. Brennan, and M.E. Smith (2009). 'Study of Railroad Rates: 19852007. Surface Transportation Board, Office of Economics, Environmental Analysis \& Administration Section of Economics

Kaylen, M.S., J.W. Wade \& D.B. Frank (1992). 'Stochastic trend, weather and US corn yield variability.' Applied Economics 24:5, pp. 513-518

National Grain Car Council (2011). Evolution of Grain and Transportation. White Paper

O'Rourke, K.H. and J.G. Williamson (1999). Globalization and History: The Evolution of a Nineteenth-Century Atlantic Economy. Cambridge, MA: MIT Press.

Rottemberg, (1982). 'Sticky Prices in the United States.' Journal of Political Economy 90:6, pp. $1187-1211$.

Schlenker, W. and M.J. Roberts (2006). 'Nonlinear Effects of Weather on Corn Yields.' Applied Economic Perspectives and Policy 28:3, pp. 391-398.

Sharp, P.R. and J.L. Weisdorf (2013). 'Globalization Revisited: Market integration and the wheat trade between North America and Britain from the Eighteenth Century.' Explorations in Economic History 50, pp. 88-98.

Surface Transportation Board (various). Annual Report.

(Available at: http://www.stb.dot.gov/stb/about/annual.html).

Uebele, M. (2011). 'National and international market integration in the 19th century: Evidence from comovement.' Explorations in Economic History 48:2, pp. 226-242.

Wolf, H.C. (2000). 'Intranational Home Bias in Trade.' Review of Economics and Statistics 82:4, pp. 555-563. 
Figures

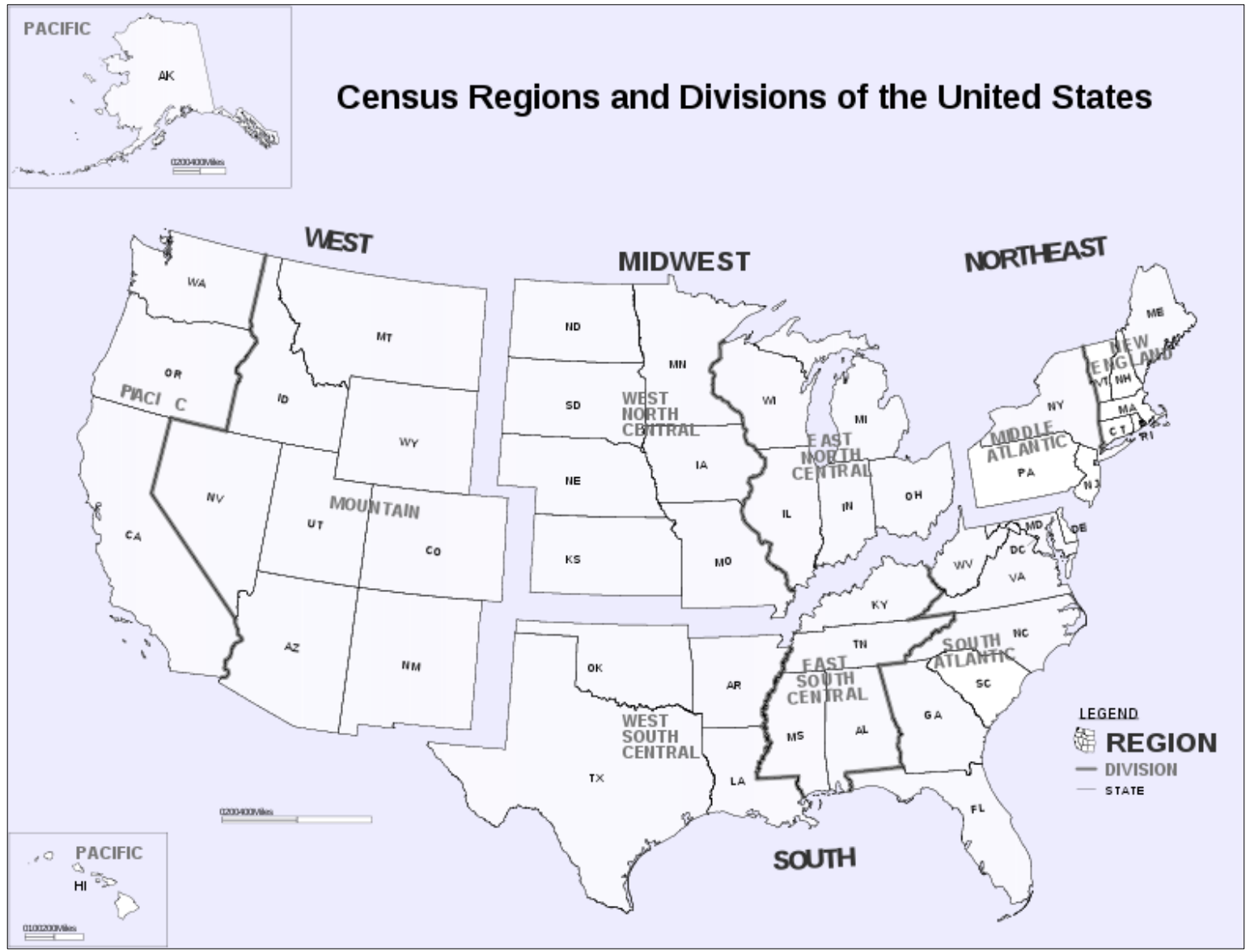

Figure 1: Census Regions of the United States

Source: US Bureau of the Census 

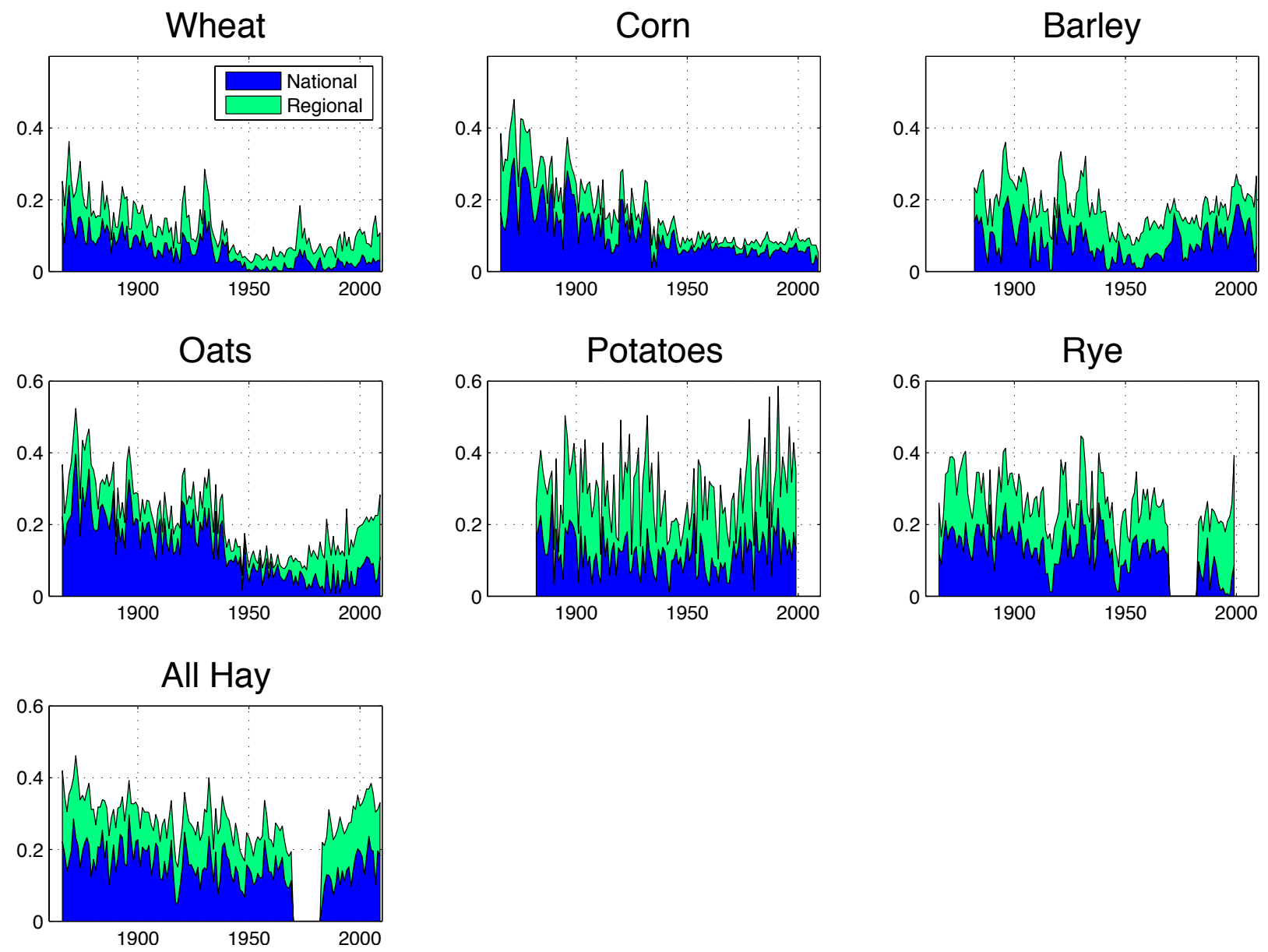

Figure 2: Coefficient of variation of prices for six selected agricultural products, 1860-2010

Source: Own calculations.

Notes: Blue is variance share between census regions and thus at national level. Green is variance share between states in the four census regions and thus at regional level. 